\title{
A Self Learning Fuzzy Logic Controller for Ship Steering System
}

\author{
Ammar A. Aldair \\ Electrical Engineering Department \\ Engineering College \\ University of Basrah, Iraq
}

Emile: mmr.ali2@googlemail.com

\begin{abstract}
A self learning fuzzy logic controller for ship steering systems is proposed in this paper. Due to the high nonlinearity of ship steering system, the performances of traditional control algorithms are not satisfactory in fact. An intelligent control system is designed for controlling the direction heading of ships to improve the high efficiency of transportation, the convenience of manoeuvring ships, and the safety of navigation. The design of fuzzy controllers is usually performed in an ad hoc manner where it is hard to justify the choice of some fuzzy control parameters such as the parameters of membership function. In this paper, self tuning algorithm is used to adjust the parameters of fuzzy controller. Simulation results show that the efficiency of proposed algorithm to design a fuzzy controller for ship steering system.
\end{abstract}

Keywords: Self Learning, Fuzzy controller, Ship Steering.

\section{تصميم منظومة تحكم من نوع المنطق المضبب ذاتية التعليم للسيطرة على دفة السفينة}
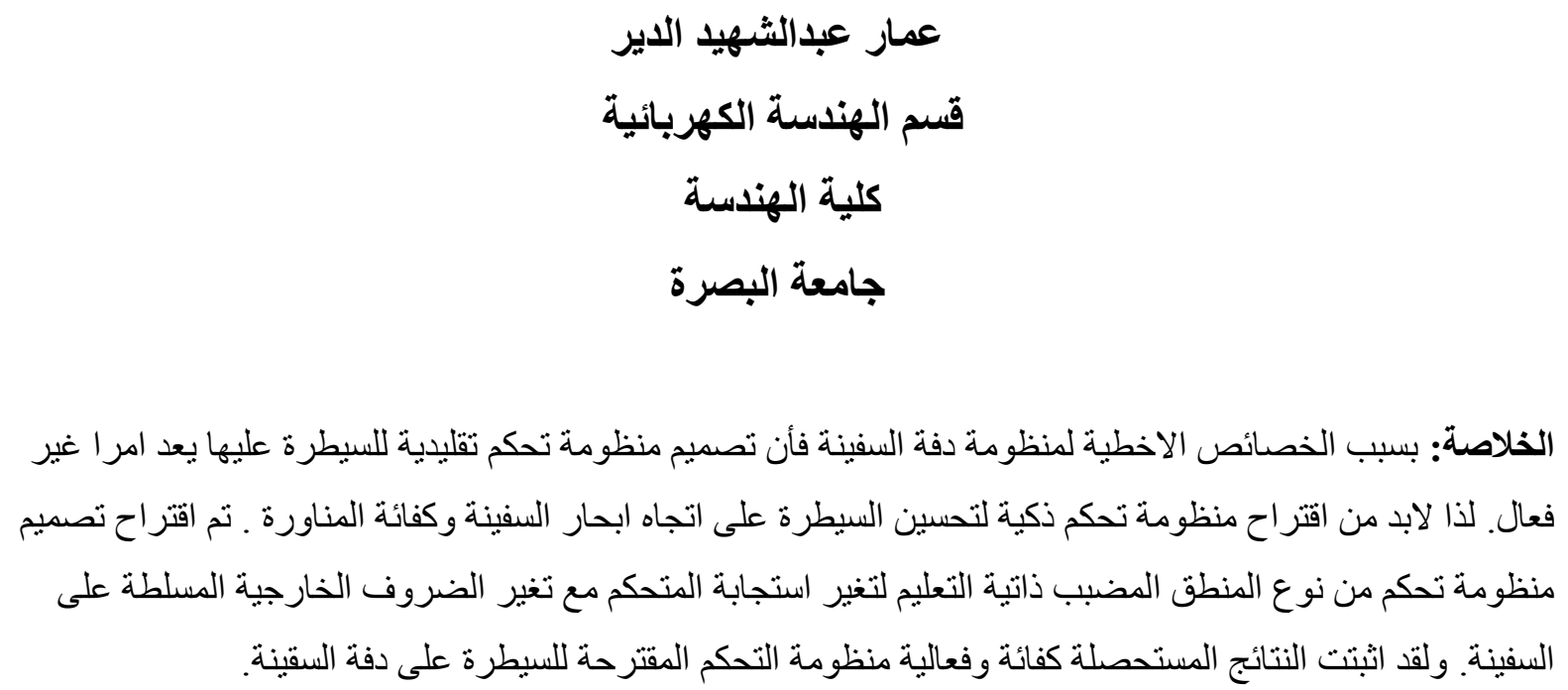


\section{Introduction}

Microprocessor and sensor technology have been applied to build automated ships to offer diverse information for safe navigation to reduce the occurrence of human error in ship operation and achieve labour cost reduction. Due to the complexity of ship motion and the randomizing of unpredictable environmental influences, the performances of traditional control algorithms are not satisfactory.

Some works are carried out to design a robust control system for ship steering autopilot. Layne and Passino used the fuzzy model reference learning control for ship steering system [1]. In reference [2], an ontology-based fuzzy support agent for ship steering control and desires to testify the validity of the proposal by applying the fuzzy control model to the steering control system based on linguistic instruction. A neural network based model reference adaptive control approach for controlling the direction heading of ships [3]. In reference [4], the authors proposed an intelligent voice instruction-based learning method and discuss the building of a ship's steering control system based on this method. Yang et al. presented a novel model reference adaptive robust fuzzy control algorithm for ship steering autopilot [5].

The fuzzy control system is successfully applied in some application area. The design of fuzzy controllers is usually performed in an ad hoc manner where it is hard to justify the choice of some fuzzy control parameters such as the parameters of membership function. In this case, a self-learning fuzzy system is effective to overcome these difficulties, as it possesses the capability of self-improvement of its performance over time. Many authors proposed a learning algorithm to make the fuzzy control system self tuning and adaptive. Some of them used learning ability of the neural networks to tune parameters of the membership function of the fuzzy inference systems $[6,7]$. The learning mechanism of fuzzy model reference learning model employs a reference model to provide a closed-loop performance feedback for synthesizing and tuning the controller's knowledge base [8,9]. Some authors used the genetic algorithm to tune the parameters of the fuzzy logic system $[10,11]$.

In this paper, the self learning fuzzy controller that utilizes a sensitivity model and second-order reference model is proposed as a control system for controlling the direction heading of ships. In order to determine a sensitivity function, the function describing the dependence of two variables (or variables and parameters) must be differentiable. There is a class of fuzzy controllers widely used in practical applications, usually called the TakagiSugeno zero-order (or singleton) fuzzy controllers, which can be organized to assume an analytical and differentiable form. Some authors used this method to design a control system for different application [12-15].

The paper is organized as follows: Section 2 presents the nonlinear dynamic model of ship steering system. In section 3, the structure of the self learning fuzzy control based on sensitive functions is described. In section 4, numerical simulation is made to demonstrate the learning phase of the fuzzy controller for ship steering system. Finally, the conclusion is summarized in section 5 .

\section{Nonlinear Dynamic Model of Ship Steering System}

Ship steering dynamic model is obtained by applying Newton's Laws of motion. The coordinate system that is fixed to the ship is describing the motion of the ship as shown in Figure 1. 


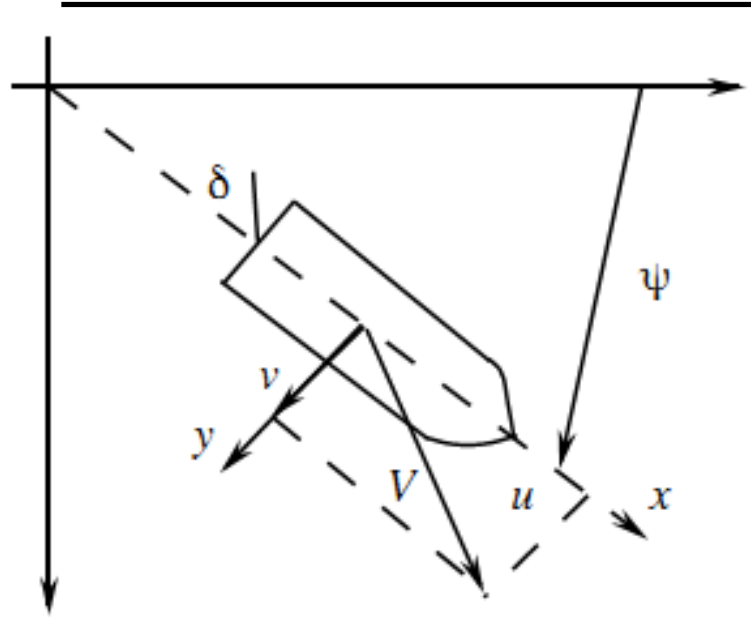

Figure 1 the coordinate system for the ship

A simple model of the ship's motion is governed by the following equation [1]:

$$
\begin{array}{r}
\dddot{\psi}(t)+\left(\frac{1}{\tau_{1}}+\frac{1}{\tau_{2}}\right) \ddot{\psi}(t)+\left(\frac{1}{\tau_{1} \tau_{2}}\right) \dot{\psi}(t) \\
=\frac{K}{\tau_{1} \tau_{2}}\left(\tau_{3} \dot{\delta}(t)+\delta(t)\right)
\end{array}
$$

where $\psi$ is the heading of the ship and $\delta$ is the rudder angle. The Laplace transformation function for Eq. 1 at zero conditions is given as

$\frac{\psi(s)}{\delta(s)}=\frac{K\left(s \tau_{3}+1\right)}{s\left(s \tau_{1}+1\right)\left(s \tau_{2}+1\right)}$

where $K, \tau_{1}, \tau_{2}$ and $\tau_{3}$ are parameters that are a function of the ship' constant forward velocity $u$ and its length $l$.

Equation 1 is obtained by linearization the equations of the motion around the zero rudder angle. As result, the rudder angle should not exceed approximately $5^{\circ}$, otherwise the model will be inaccurate. Therefore, a model suited for rudder angles that are larger than $5^{\circ}$ should be derived. The nonlinear model that is presented in [1] is used in this study. This extended model is given by:

$$
\begin{aligned}
& \dddot{\psi}(t)+\left(\frac{1}{\tau_{1}}+\frac{1}{\tau_{2}}\right) \ddot{\psi}(t)+\left(\frac{1}{\tau_{1} \tau_{2}}\right) H(\dot{\psi}(t)) \\
& =\frac{K}{\tau_{1} \tau_{2}}\left(\tau_{3} \dot{\delta}(t)\right. \\
& +\delta(t))
\end{aligned}
$$

where $H(\dot{\psi}(t))$ is nonlinear function of $\dot{\psi}(t)$. An experiment known as the "spiral test" has shown that $H(\dot{\psi}(t))$ can be approximated by

$H(\dot{\psi}(t))=a \dot{\psi}^{3}(t)+b \dot{\psi}(t)$

where $a$ and $b$ are real valued constants such that $a$ is always positive.

\section{Self Learning Fuzzy Control Based on Sensitivity Functions}

Figure 2 shows the structure of the proposed controller (self learning fuzzy control). The concept of the SLFLC block allows control of unknown inherently stable static and astatic nonlinear systems providing that desired closed-loop system behaviour can be represented with a linear secondorder reference model. The fuzzy controller has two inputs $e(k)$ and $\mathrm{d} y(k)$ and one output $u_{F C}(k)$. The Takagi-Sugeno type of fuzzy controller is used in this structure. The fuzzy rules which map the antecedent fuzzy relations $R_{i}$ with the consequence parts containing an explicitly determined control input $u_{F C}$ :

IF $R_{i}$ THEN $u_{F C}=a_{i}$

where $a_{i}$ is constant.

The output of the fuzzy controller can be given as 


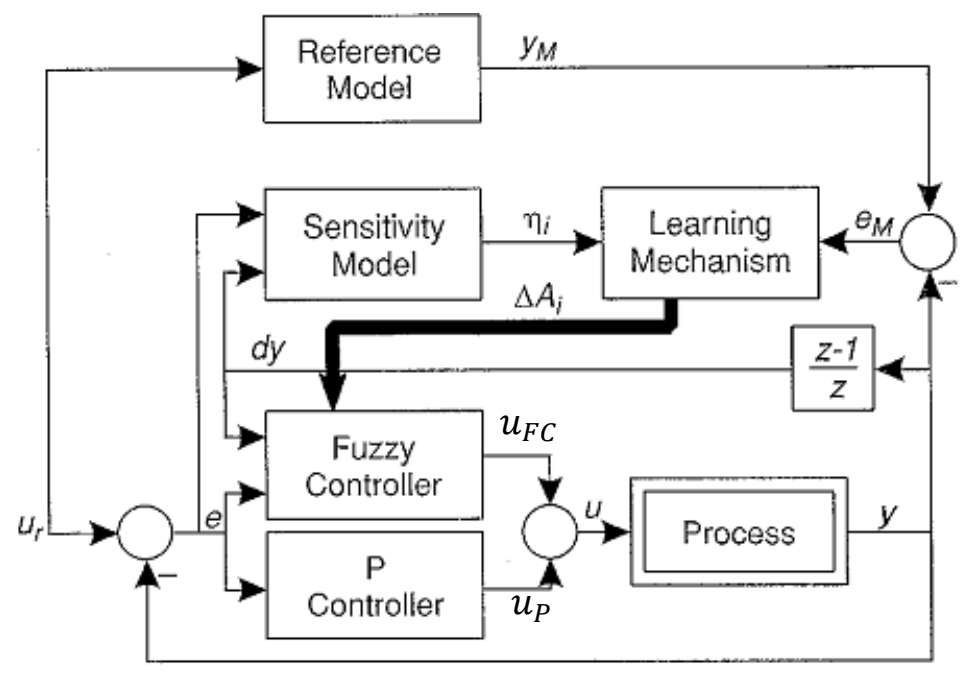

Figure 2 the structure of the self learning

fuzzy control scheme

$$
\begin{aligned}
& u_{F C}(k)=\sum_{i=1}^{r} A_{i} * \phi_{i}[e(k), \mathrm{d} y(k)] \\
& =\sum_{i=1}^{r} A_{i} * \frac{\mu_{i}[e(k), \mathrm{d} y(k)]}{\sum_{i=1}^{r} \mu_{i}[e(k), \mathrm{d} y(k)]}
\end{aligned}
$$

where $A_{i}$ is the centroid of the fuzzy controller output subset activated by the $i^{\text {th }}$ fuzzy rule; $e(k)=u_{r}(k)-y(k) ; d y(k)=y(k)-y(k-1) ;$ $r$ is the number of fuzzy rule; and $\mu_{i}$ is the member function of a fuzzy implication.

The input control signal to the process can be given as:

$u(k)=u_{F C}(k)+K_{P} * e(k)$

where $K_{P}$ is proportional gain.

The second order reference model is used to determine the desired closed loop system. The transfer function of the reference model is given as:

$\frac{Y_{m}(s)}{U_{r}(s)}=\frac{\omega_{n}^{2}}{s^{2}+2 \eta \omega_{n} s+\omega_{n}^{2}}$ where $y_{m}(k)$ is the desired output; $u_{r}(k)$ is the reference input; $\eta$ is damping ratio; and $\omega_{n}$ natural oscillation frequency.

Sensitivity functions can be very useful to express how much influence some variables or parameters have on the focused variable. In this sense, sensitivity functions represent information about interactions between causes and consequences which may be very useful for planning interventions in the system. Having this concept in mind, a total differential of the system output $y(k)$ with respect to small variations of controller parameters is determined by

$$
\begin{aligned}
\Delta y(k)=\sum_{i=1}^{N} \frac{\partial y(k)}{\partial \lambda_{i}} * \Delta \lambda_{i} \\
=\sum_{i=1}^{N} \xi_{\lambda i}(k) * \Delta \lambda_{i}
\end{aligned}
$$

where $\lambda_{i}$ is $i^{\text {th }}$ fuzzy controller parameter; $\xi_{\lambda i}(k)$ is the sensitive function related to parameter of the fuzzy controller.

By using the chain rule, the sensitive function can be written as

$$
\begin{aligned}
\xi_{\lambda i}(k)=\frac{\partial y(k)}{\partial \lambda_{i}} & =\frac{\partial y(k)}{\partial u(k)} * \frac{\partial u(k)}{\partial \lambda_{i}} \\
& =G_{P} * \frac{\partial u(k)}{\partial \lambda_{i}}
\end{aligned}
$$

A sensitivity function of the controller output with respect to controller parameter variations has the form

$$
\frac{\partial u(k)}{\partial \lambda_{i}}=\frac{\partial}{\partial \lambda_{i}}\left\{\sum_{i=1}^{r} A_{i} * \phi_{i}[e(k), \mathrm{d} y(k)]\right\}
$$


In the proposed concept, system parameter variations will be compensated for only by modifying the centroid of the fuzzy output sets $A i$ (input membership functions remain predefined). Therefore

$$
\begin{aligned}
& \frac{\partial u(k)}{\partial \lambda_{i}}=\frac{\partial u(k)}{\partial A_{i}}=\frac{\partial}{\partial A_{i}}\left\{\sum_{i=1}^{r} A_{i} * \phi_{i}[e(k), \mathrm{d} y(k)]\right\} \\
& =\frac{\partial}{\partial A_{i}}\left\{\sum_{i=1}^{r} A_{i} * \frac{\mu_{i}[e(k), \mathrm{d} y(k)]}{\sum_{i=1}^{r} \mu_{i}[e(k), \mathrm{d} y(k)]}\right\} \\
& =\frac{\mu_{i}[e(k), \mathrm{d} y(k)]}{\sum_{i=1}^{r} \mu_{i}[e(k), \mathrm{d} y(k)]}
\end{aligned}
$$

Therefore, the update equation of the centroid of the fuzzy controller output is given as

$$
\begin{aligned}
& A_{i}^{\theta+1}=A_{i}^{\theta}+\frac{\partial u(k)}{\partial A_{i}} \\
& =A_{i}^{\theta}+\frac{\mu_{i}[e(k), \mathrm{d} y(k)]}{\sum_{i=1}^{r} \mu_{i}[e(k), \mathrm{d} y(k)]}
\end{aligned}
$$

\section{Simulation and Results}

The nonlinear model of the ship steering, which is given in Eq. 3, is used to demonstrate the effectiveness of the self learning fuzzy control algorithm. For our simulations, the values of both $a$ and $b$, which are shown in Eq. 4, are chosen to be 1. The reference model is defined as: $\omega_{n}=0.05$ and $\eta=1$.

The type of the fuzzy controller that had been used in this simulation is Takagi-Sugeno type. To design the fuzzy controller, the triangular membership functions are used for the input variables as shown in Figure 3. While the singleton membership functions are used for the output variable with random centroid values.

Eighty one rules are used to describe the fuzzy rules based as shown in Table 1, where the values of the variable $a_{i}$ for $i \in\{1,81\}$ are arbitrary value.

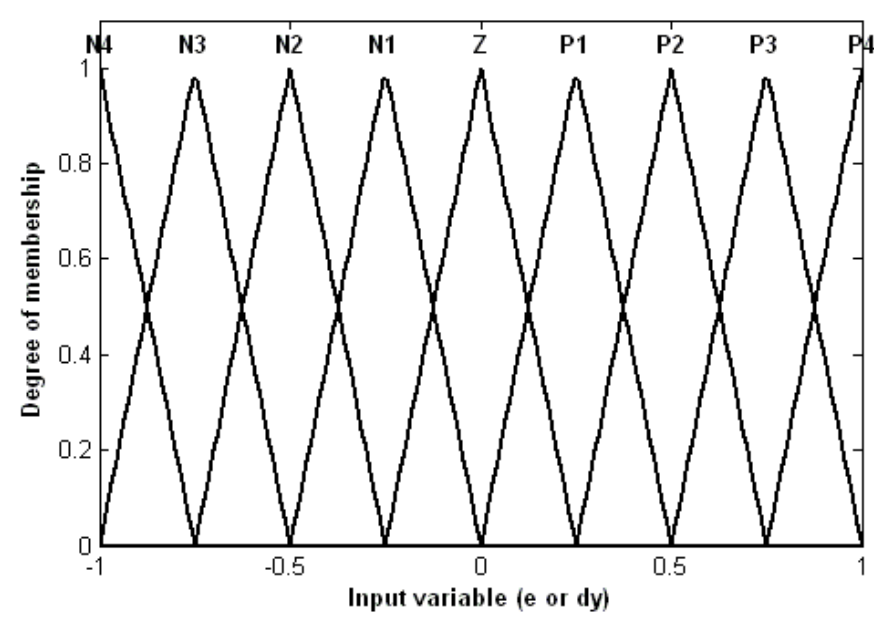

Figure 3 Triangular membership functions for the input variable

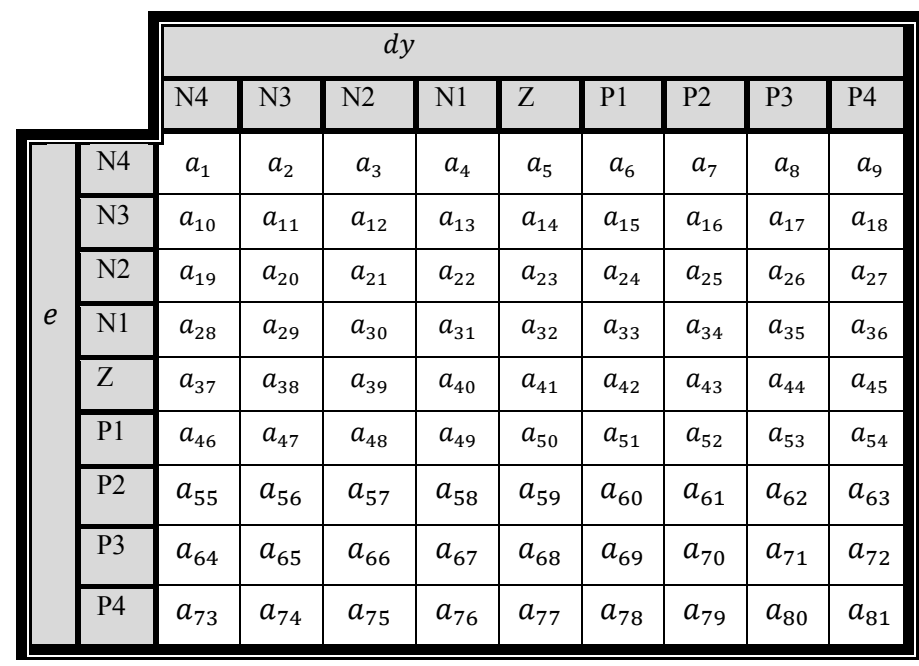

Table 1 The rules of the fuzzy controller For any fuzzy logic controller design, it is necessary to check the surfaces between the proposed membership function and the control action in order to make sure of the rounding process inside the fuzzy system. Figure 4 shows the control surface (before tuning the parameters of output membership function) between inputs/output variables using the proposed membership functions. 


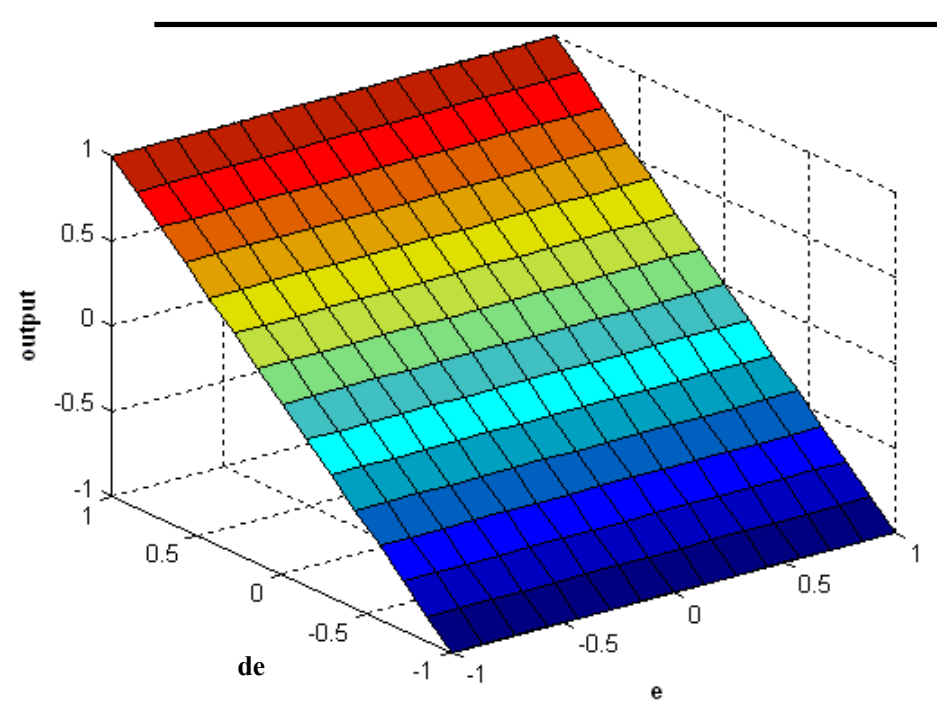

Figure 4 Control surface between inputs and output variables (before tuning)

The self learning Fuzzy Control Based on Sensitivity Functions is used to tune the parameters of the output membership functions of the fuzzy controller. Figure 5 depicts the structure of the self learning fuzzy controller with ship steering model during the training phase. It can be seen that the self learning fuzzy controller is acting in parallel with compensator controller. This means that the fuzzy controller acts like an adaptation mechanism, having a goal to improve the overall system performance. The internal model control algorithm is used to select the optimal parameters of the compensator block. The structure of the compensator block that is used in this simulation can be obtained from Control System Toolbox in MATLAB and it is given as:

$\frac{U(s)}{E(s)}=\frac{-3.43 s-0.12}{2230 s^{3}+194.48 s^{2}+s}$

The update equation 13 is used to tune the parameters of the fuzzy controller. After 21 iterations the optimal values of the centroid of the fuzzy controller output can be obtained. Table 2 shows the tuned centroid parameters.

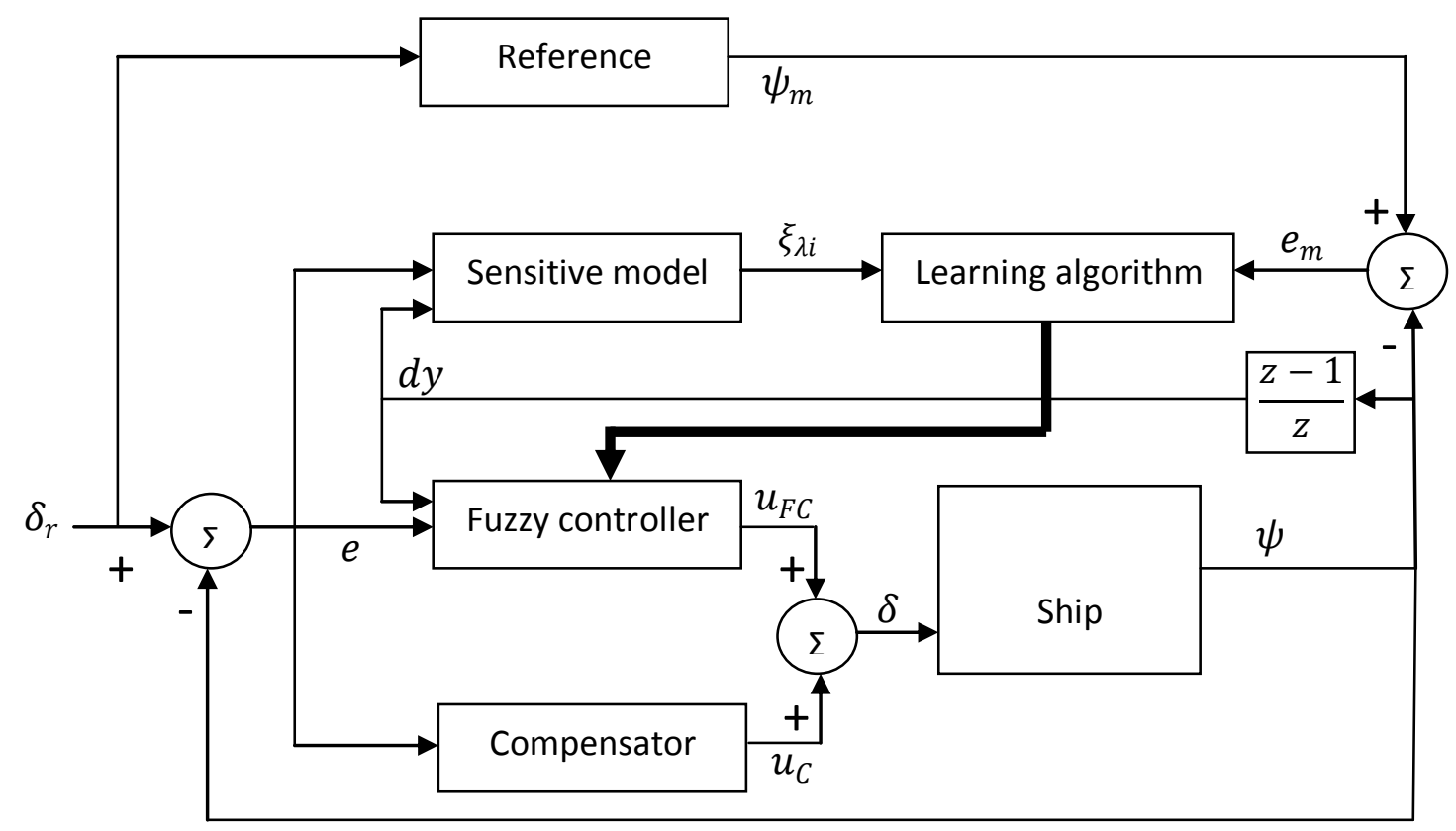

Figure 5 the structure of the self learning fuzzy controller with ship 
Table 2 The parameters of the centroid of the fuzzy controller output after tuned

\begin{tabular}{|l|l|l|l|l|l|l|l|l|}
\hline 9.271 & 3.269 & 1.034 & 0379 & -0.591 & 0 & 0 & 0.911 & -0.106 \\
\hline-1.717 & -1.548 & 0.221 & -0.611 & -1.702 & 0 & 0 & 0.663 & -1.339 \\
\hline 2.405 & 0.148 & 0.012 & -0.519 & 1.766 & 0 & 0 & 4.522 & 2.174 \\
\hline 2.259 & 0.639 & 0.82 & 2.058 & -1.403 & 0 & -0.004 & -1.153 & -1.287 \\
\hline-4.629 & 0.430 & 1.255 & -2.267 & -4.25 & 0 & 0.139 & -1.920 & -3.075 \\
\hline 0 & 0 & 0 & 0 & 0 & 0 & 0 & 0 & 0 \\
\hline 0.153 & 1.298 & 0.066 & 0 & -0.159 & 0 & 0 & 0 & -0.159 \\
\hline-1.783 & -2.573 & -0.539 & 0 & 5.214 & 0 & 0 & 4.716 & 4.398 \\
\hline-1.508 & -1.61 & -3.27 & 0 & -8.461 & 0 & 0 & -6.91 & -6.637 \\
\hline
\end{tabular}

Figure 6 and Figure 7 show the reference input, ship steering system output, and reference model responses for the first six iterations and for the last four iterations, respectively. It can be seen that after completion of learning process the direction heading of the ship follows the reference model response. The output of ship steering system with a compensator controller has high overshoot and reaches the steady state after eight seconds, while the hybrid self-learning fuzzy controller enforces system to reach the steady state in less than two seconds without overshoot. This proves that addition of the SLFLC in parallel to the compensator block has contributed to a much better quality of the system response.

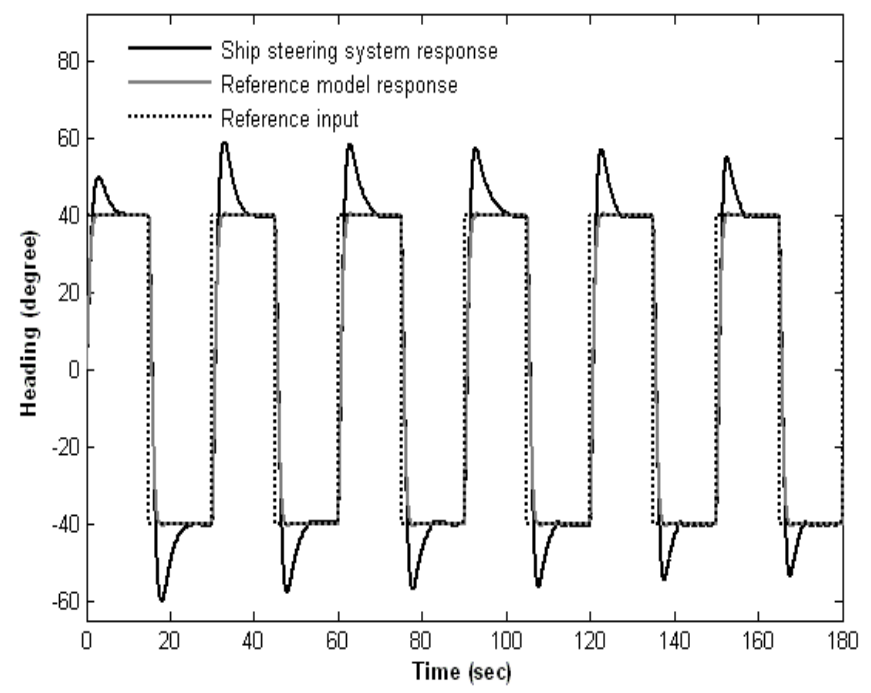

Figure 6 the responses for the first six iterations

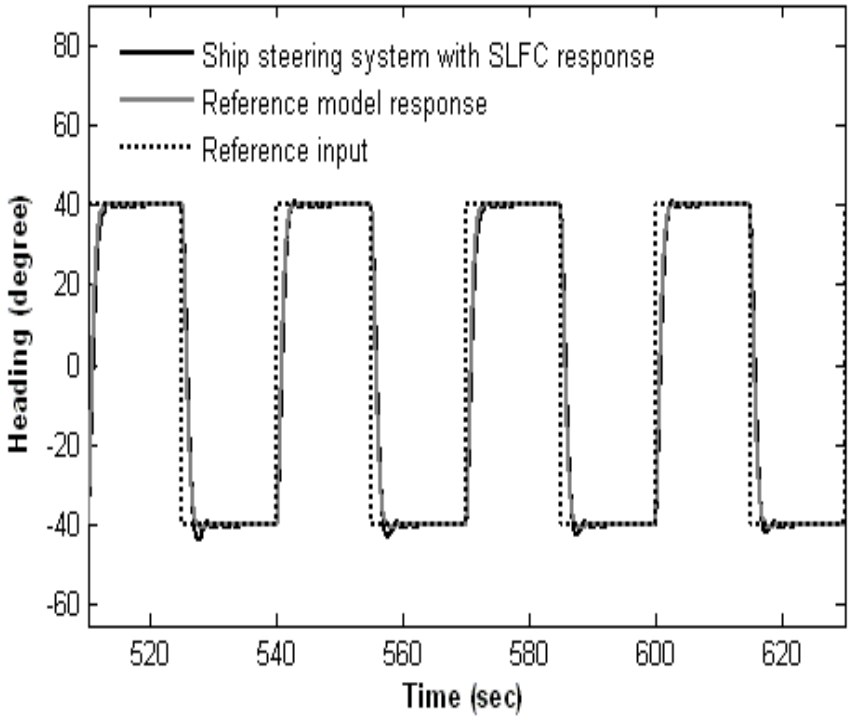

Figure 7 the responses for the last four iterations

Figure 8 and Figure 9 show the hybrid self-learning fuzzy controller outputs at the beginning of learning (almost just the compensator controller is active) and at the end of learning (both controllers are active). 


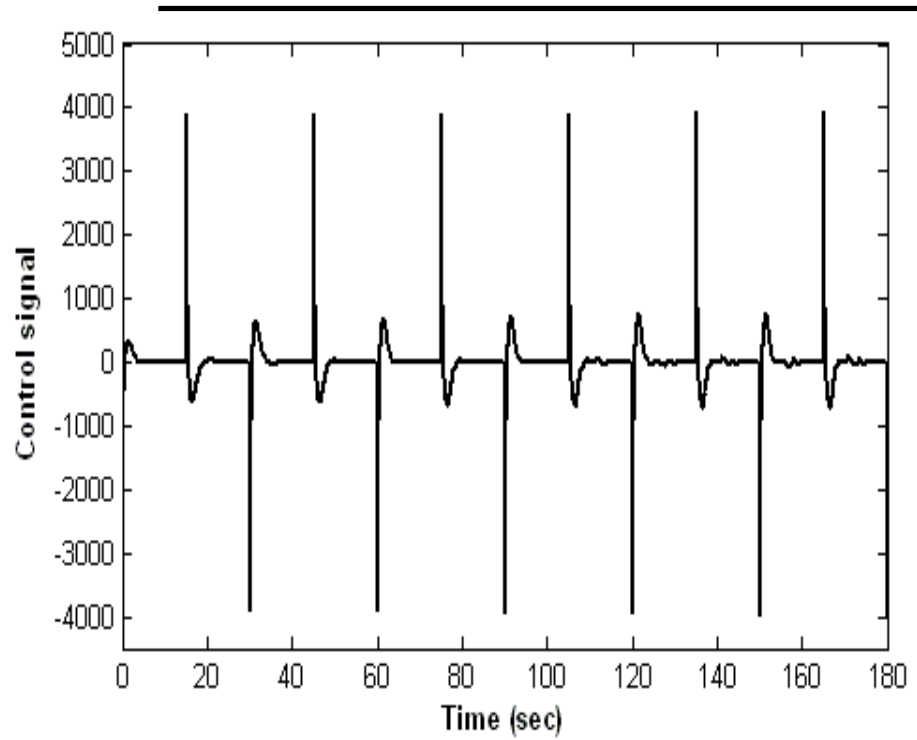

Figure 8 the responses for the first six iterations

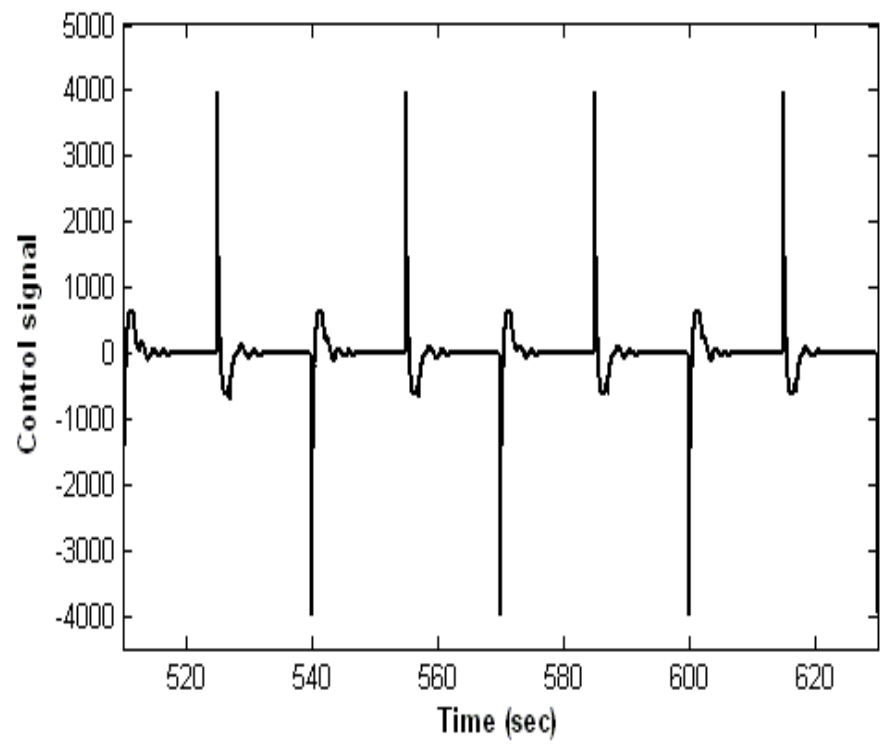

Figure 9 the responses for the last four iterations

Figure 10 shows the control surface (after the process of the training is completed) between inputs/output variables using the proposed membership functions

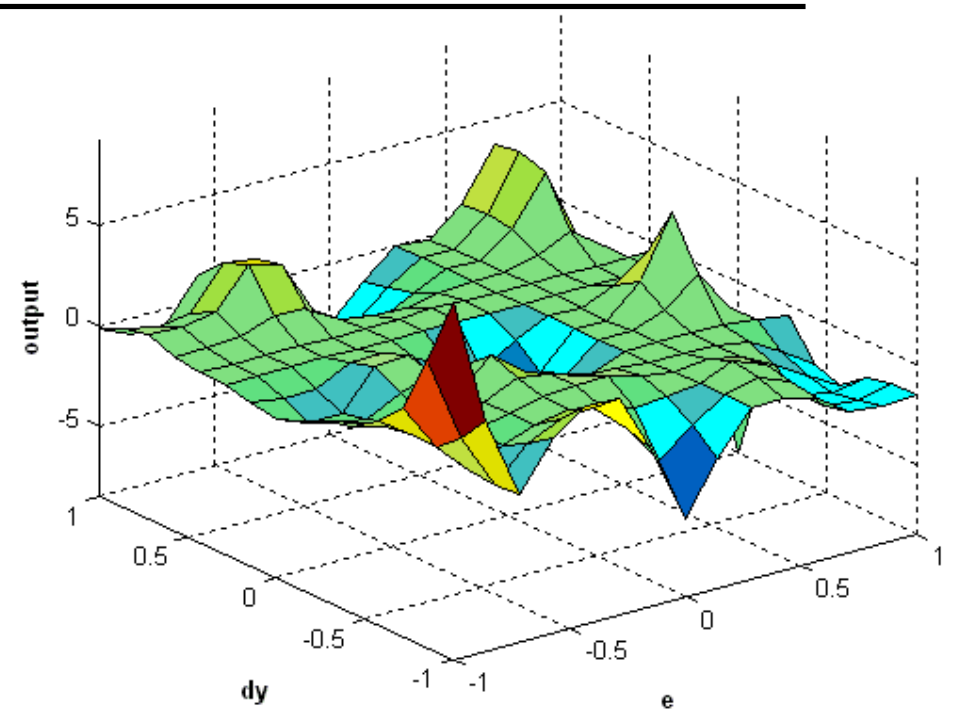

Figure 10 Control surface between inputs and output variables (after tuning)

\section{Conclusion}

The self learning Fuzzy Control Based on Sensitivity Functions is effectively used to tune the parameters of the output membership functions of the fuzzy controller for controlling the direction heading of the ships. The simulation results show that after completion of learning process the direction heading of the ship follows the reference model response. The output of ship steering system with a compensator controller has high overshot and reaches the steady state after eight seconds. But when the hybrid self-learning fuzzy controller is acting in parallel with compensator controller, the overshoot of the output response of the ship steering system is omitted and the steady state enforces to be reached in less than two seconds. 


\section{References}

1. Layne, J.R. and K.M. Passino, Fuzzy Model Reference Learning Control for Cargo Ship Streering. IEEE Control System Magazine, Vol. 13, No. 6, 1993, pp. 23-34.

2. Seo, K., et al., Ontology-based Fuzzy Support Agent for Ship Steering Control. Expert Systems with Applications, Vol. 36, 2009, pp. 755-765.

3. Cheng, J., J. Yi, and D. Zhao, Neural Network Based Model Reference Adaptive Control for Ship Steering System International Journal of Information Technology, Vol.11, No, 6, 2005, pp. 75-82.

4. Seo, K., et al., Intelligent Steering Control System Based on Voice Instructions. International Journal of Control, Automation and Systems, Vol. 5, No.5, 2007, pp. 539-546.

5. Yang, Y., C. Zhou, and J. Ren, Model Reference Adaptive Robust Fuzzy Control for Ship Steering Autopilot with Uncertain Nonlinear Systems. Applied Soft Computing, Vol.3, 2003, pp. 305-316.

6. Berenij, H.R. and P. Khedkar, Learning and Tuning Fuzzy Logic Controllers Through Reinforcements. IEEE Trans. Neural Networks, Vol.3, 1992, pp. 724 - 740.

7. Jang, R., Self Learning Fuzzy Controller based on temporal back propagation. IEEE Trans. Neural Networks, Vol.3, 1992, pp. 714-723.

8. King, P.J., K.J. Burnham, and D.J.G. James, $A$ Model Reference Self Organizing Fuzzy Logic Controller Control and Computers, Vol. 23, No. 1, 1995.

9. Bogdan, S. and Z. Kovacic. On the Design of Self Learning Fuzzy Controllers for Nonlinear Control Systems by Using a Reference Model and a Sensitivity. in Proceeding of the 4th IEEE
Mediterranean Symposium on Control and Automation. 1996. Chania.

10.Chiang, C., H. Chung, and J. Lin, A Self Learning Fuzzy Logic Controller Using Genetic Algorithms with Reinforcements IEEE trans. on Fuzzy Systems, Vol.5, No. 3, 1997, pp. 460-467.

11.Lee, M.A. and H. Takagi. Integrating Design Stages of Fuzzy Systems using Genetic Algorithms. in Proc. of the 2nd Int'l Conf. on Fuzzy Systems. 1993.

12.Kovacic, Z., S. Bogdan, and M. Balenovic, $A$ Model Reference \& Sensitivity Model-based Selflearning Fuzzy Logic Controller as a Solution for Control of Nonlinear Servo Systems IEEE Transactions on Energy Conversion, Vol.14, No. 4, 1999, pp. 1479-1484.

13.Kovacic, Z., M. Balenovic, and S. Bogdan, Sensitivity-based self-learning fuzzy logic control for a servo system. IEEE Control System Magazine, Vol.18, No. 3, 1998, pp. 41-51.

14.Huang, S. and W. Lin, A Self-Organizing Fuzzy Controller for an Active Suspension System. Journal of Vibration and Control, Vol. 9, 2003, pp. 1023-1040.

15.Bech, M. and L. Smitt, Analogue simulation of ship maneuvers. 1969, Hydro-og Aerodynmisk Laboratorium: Lyngby, Denmark. 